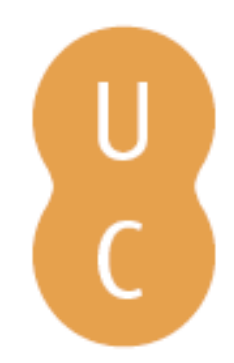

\title{
pommalina
}

\section{A minha vida não dava um filme: ensaio de desconstrução da reportagem entre a literatura e o jornalismo}

\author{
Autor(es): $\quad$ Godinho, Jacinto \\ Publicado por: Imprensa da Universidade de Coimbra \\ URL \\ persistente: URI:http://hdl.handle.net/10316.2/41348 \\ DOI: $\quad$ DOI:https://doi.org/10.14195/978-989-26-1324-6_7 \\ Accessed : $\quad$ 26-Apr-2023 01:05:34
}

A navegação consulta e descarregamento dos títulos inseridos nas Bibliotecas Digitais UC Digitalis, UC Pombalina e UC Impactum, pressupõem a aceitação plena e sem reservas dos Termos e Condições de Uso destas Bibliotecas Digitais, disponíveis em https://digitalis.uc.pt/pt-pt/termos.

Conforme exposto nos referidos Termos e Condições de Uso, o descarregamento de títulos de acesso restrito requer uma licença válida de autorização devendo o utilizador aceder ao(s) documento(s) a partir de um endereço de IP da instituição detentora da supramencionada licença.

Ao utilizador é apenas permitido o descarregamento para uso pessoal, pelo que o emprego do(s) título(s) descarregado(s) para outro fim, designadamente comercial, carece de autorização do respetivo autor ou editor da obra.

Na medida em que todas as obras da UC Digitalis se encontram protegidas pelo Código do Direito de Autor e Direitos Conexos e demais legislação aplicável, toda a cópia, parcial ou total, deste documento, nos casos em que é legalmente admitida, deverá conter ou fazer-se acompanhar por este aviso.

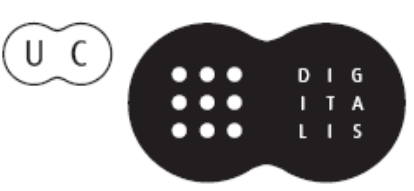





\section{A MINHA VIDA NÃO DAVA UM FILME: ENSAIO DE DESCONSTRUÇÃO DA REPORTAGEM ENTRE A LITERATURA E O JORNALISMO}

Jacinto Godinho

Universidade Nova de Lisboa

Apesar de ser considerada, entre os jornalistas, como a "arte nobre do jornalismo" a reportagem tem sem dúvida um estatuto menor no painel das narrativas modernas, especialmente se a compararmos com as mais relevantes categorias da literatura (novela, conto, poema) do cinema (filme, documentário) do teatro ou da música (ópera) por exemplo.

Não que a reportagem seja uma narrativa menor (apesar de nos últimos anos ter vindo a ceder espaço nos media para o comentário), mas porque, ecoando Foucault, nas formações discursivas de cada época constitui-se uma escala de valores entre saberes originada a partir do jogo do poder.

A cultura não celebra as reportagens e os seus autores da mesma forma que as ficções literárias e cinematográficas distinguidas com prémios de visibilidade planetária como o Nobel ou os Oscar.

Fora do campo jornalístico não há reportagens que façam história, que figurem nos livros de escola. Em busca de estatuto, alguns repórteres tornam-se autores de livros de ficção. Outros publicam as suas reportagens em livros. Muitos livros se escreveram baseados em 
trabalhos antes publicados na imprensa (A Sangue Frio de Truman Capote, Balada da Praia dos Cães de José Cardoso Pires) e muitos nomes célebres da literatura foram primeiro jornalistas como Gabriel Garcia Márquez, Ernest Hemingway, Mark Twain. Em Portugal, entre inúmeros casos, podemos destacar alguns nomes como Aquilino Ribeiro, Raul Brandão, José Saramago, Miguel Sousa Tavares, José Rodrigues dos Santos. Para muitos destes jornalistas o treino de escrita de reportagem é assumido, com orgulho, como um patamar essencial para se tornarem escritores, ou seja, praticam a reportagem como etapa antes da literatura. Mas não deveria ser antes o oposto, ou seja, o ensaio livre da literatura como antecâmara para a difícil, complexa e muito responsável escrita do real?

Justifica-se, portanto, iniciar esta reflexão analítica com a pergunta já antes formulada por Elisabeth Eide em What novels can do, and journalism can not? ${ }^{61}$, ou seja, o que conseguem as novelas que o jornalismo não consegue?

Uma outra forma de colocar o problema é questionar por que dizemos normalmente "a minha vida dava um filme" e não dizemos "a minha vida dava uma reportagem".

Porque nunca conseguiram os repórteres ter lugar nos panteões da cultura, se a matéria das suas histórias é a vida real e tantas vezes o alimento dos romancistas?

Como resolver o paradoxo de o jornalismo e de o poder mediático serem centrais no espaço público moderno e mesmo assim não conseguirem "fazer ver e fazer falar" (Deleuze, 1986) as suas melhores obras na história?

Levando em conta os critérios de Foucault, será a narrativa de reportagem um saber sujeitado, que pertence "a toda uma classe de saberes que estavam desqualificados como saberes não conceptuais,

\footnotetext{
${ }^{61}$ Eide, Elisabeth. "What novels can do, and journalism can not. On the relationship between fiction and reportage". http://home.hio.no/ elisabe/english.htm [cons. 13-7-2015]
} 
como saberes insuficientemente elaborados, saberes ingénuos, saberes hierarquicamente inferiores." (Foucault, 1975: 11-12).

Entre as muitas razões para esta possível "sujeitação" estará, sem dúvida, o histórico conflito entre a filosofia e o jornalismo. Desde o século XVIII que a narrativa jornalística tem sido fortemente submetida a uma forte desqualificação pelo predominante e hegemónico discurso científico, por não se enquadrar nos postulados de cientificidade. Aliás, tanto "jornalista" como "reportagem" começaram por ser dois nomes estigmatizados destinados a rebaixar a atividade que passaram a referir. Denis Diderot qualificou na Encyclopédie os jornais de "publicações que são o alimento do ignorante, o recurso de quem quer falar e julgar sem ler, o flagelo e nojo de quem trabalha. Eles nunca ajudaram um bom espírito a produzir uma boa escrita; ou impediram um escritor ruim de fazer um livro ruim." (Diderot, 1766). Voltaire nos seus Conseils à un Journaliste conclui a lição suspirando:

\footnotetext{
Quisera Deus que fosse fácil remediar o mal que produzem todos os dias tantos escritos mercenários, tantos estratos infiéis, tantas mentiras e calúnias com que a imprensa inunda a república das letras! (Voltaire, 1737: 41)
}

"Jornalista" e "reportagem" eram, portanto, representações achincalhantes no discurso das elites antes de se naturalizarem como nomes sérios e neutros na cultura moderna. Este processo de desqualificação da reportagem culminou naquilo que apelidámos a "maldição de Mallarmé" (Godinho, 2009).

Num pequeno, mas célebre, texto de 1897 intitulado Crise de Vers Mallarmé procura refundar a essência da literatura opondo-a dialeticamente ao que chamou a "universal reportagem". Para Mallarmé a literatura na sua essência é o verso livre. Livre de rimas, de métrica, de melodia e de história. A isso se opõe a escrita utilitária, feita 
de truques comerciais para agradar aos outros, vendendo fórmulas repetidas disfarçadas de novidades. Tudo o que é odioso na escrita encaixa na "universal reportagem".

Mallarmé usou, portanto, a palavra reportagem como critério negativo de uma ideologia que a opunha ao conceito raro de literatura, prolongando-lhe o estigma no campo das artes. Tese mais tarde continuada pelos surrealistas. Breton apelidou de "devorador", "cretinizante" confucionista o jornalismo ${ }^{62}$. O surrealismo foi um dos movimentos que mais insistiu na separação entre "obras vivas" e "escritos de jornal", contribuindo para uma das oposições emblemáticas do século XX, o par literatura vs. jornalismo.

Talvez a "maldição de Mallarmé", prolongada pelo século XX e até aos nossos dias, explique ou seja sintoma do fraco investimento académico no estudo e entendimento das especificidades narrativas da reportagem, das técnicas e da forma como se inscreve na experiência.

Este ensaio procura, portanto, aprofundar uma análise já antes iniciada a partir da pergunta "O que é a reportagem?" (Godinho, 2009) para aclarar os princípios narrativos da experiência que a sustenta e, assim, entrar com fundamento no debate entre jornalismo e literatura.

John Carey no seu livro The Faber Book of Reportage define como critério fundamental para definir uma reportagem o relato diretamente observável pelo próprio ou por testemunhas (Carey, 1996). Carey considera mesmo alguns excertos de livros de ficção como momentos de escrita de reportagem porque são relatos tão credíveis que só podem ter sido baseados em experiências reais. Aponta o caso da descrição que Stendhal faz da batalha de Waterloo através do testemunho do protagonista Fabrício. Trata-se de uma ficção mas com uma coerência muito verosímil:

\footnotetext{
${ }^{62}$ Breton, André - "Legitime defense" (1926), Point du jour, Gallimard, Coll "Idées", pp. 33-36.
} 
Havia já muito tempo que Fabrício deixara de ver a terra voando em migalhas sob a ação de metralha. Chegaram à retaguarda dum regimento de couraceiros. Fabrício ouvia distintamente os biscainhos batendo as couraças e viu cair alguns homens.

O Sol já estava muito baixo no horizonte, e ia pôr-se quando a escolta, saindo dum caminho profundo, subiu uma pequena rampa de três ou quatro pés para entrar num campo lavrado. Fabrício distinguiu a seu lado um ruído estranho; voltou a cabeça: quatro homens tinham caído com os cavalos; o próprio general havia sido derrubado, mas já se erguia, todo coberto de sangue. Fabrício contemplava os hussardos caídos por terra: três tinham ainda alguns movimentos convulsivos, o quarto gritava: Tirem-me daqui debaixo! O sargento e dois ou três homens tinham-se apeado para socorrer o general que, apoiando-se ao seu ajudante-de-campo, tentava dar alguns passos; procurava afastar-se do cavalo, que se debatia por terra, dando coices furibundos (Stendhal, 1974:55).

O princípio da observação direta postulado por Carey coloca o seguinte problema: será que não se podem fazer reportagens de fenómenos não diretamente observáveis como a corrupção, a inflação, a depressão por exemplo? Fenómenos complexos e normalmente apresentados em reportagens através de casos escolhidos como emblemáticos como se de apenas uma árvore se conseguisse ver toda a floresta.

O princípio do diretamente testemunhável parece ser limitado no seu empirismo básico. Mas na reportagem existe uma ligação íntima entre o olhar e a palavra. Se entendermos o princípio de Carey como uma base de trabalho isso significa que a prática da reportagem exige que os repórteres procurem, mesmo nos casos mais complexos, o que pode ser diretamente observável. 
Por exemplo, tomemos o caso da inflação, um real abstrato. Para tratar um fenómeno destes um repórter normalmente pega no modelo da tese académica, divide o tema em várias categorias, como a política, a economia, a jurídica, etc., procura para cada uma um especialista, alterna o seu testemunho com uma série de exemplos escolhidos ao acaso de produtos que subiram ou desceram de preço e acrescenta-lhe vozes populares (Voz Off) escolhidas ao acaso numa mercearia ou supermercado. No final, tudo reunido, é chamado uma reportagem mas parece antes catálogo ideológico. Se a orientação for o "diretamente observável", é necessário refazer a pesquisa e o guião narrativo, partindo em busca do que, no tema inflação, pode ser realmente testemunhado.

Como é realmente calculada a inflação? Que organismo faz os cálculos? Como os faz no terreno, ou seja, que produtos são monitorizados e por quem? Para seguir esta linha narrativa a reportagem precisa de tempo. A reportagem está mais do lado de uma narrativa temporal do que de uma narrativa sincrónica. Mas como funciona o testemunho, o diretamente observável, no circuito da palavra? Como é que o olhar se preserva na palavra e como guarda a reportagem a legitimidade de fazer acreditar que os acontecimentos relatados aconteceram realmente?

Regressemos então à pergunta: "o que é a reportagem?”

Quem melhor pode orientar nesta pergunta ontológica é Martin Heidegger. Heidegger não se interroga diretamente sobre a reportagem mas sobre a filosofia. Heidegger sustenta que a cultura ocidental é, no seu caminho mais íntimo, originariamente filosófica. Isto não significa que a filosofia seja a fundadora da civilização ocidental. Significa que é a filosofia quem pergunta pelo ser das coisas. As narrativas científicas estão organizadas a partir da pergunta "o que é?" por exemplo: o que é o sistema solar, um terramoto, a doença, a vida, a morte, etc.

O jornalismo, à sua maneira, também pergunta pelo ser das coisas, interrogando a atualidade: o que é a crise, o desemprego, a violência 
doméstica e assim sucessivamente. A pergunta pelo ser está enraizada tanto no núcleo mais profundo do nosso sistema epistemológico como na banalidade dos saberes quotidianos.

A filosofia vai mais longe e pergunta por que é que nós perguntamos pelo ser das coisas. A pergunta pelo ser é o motor da cultura ocidental. Mas a variedade de articulações narrativas que a pergunta do ser permite é enorme.

Walter Benjamin no ensaio "O Narrador" afirma que a tradição da narrativa tradicional não conduz a uma explicação:

\footnotetext{
Cada manhã recebemos notícias de todo o mundo. E, no entanto, somos pobres em histórias surpreendentes. A razão é que os factos já nos chegam acompanhados de explicações. Em outras palavras: quase nada do que acontece está ao serviço da narrativa, e quase tudo está a serviço da informação. Metade da arte narrativa está em evitar explicações. (Benjamin, 1994: 203).
}

Quando colocados perante a pergunta "o que é a reportagem?", somos automaticamente instalados numa situação de ignorância a que é prometida a revelação de um segredo. A expectativa da revelação é tão forte que podemos ser iludidos com a sugestão de uma explicação que promete finalmente esclarecer mas que não explica nada.

Será que responder à pergunta "o que é a reportagem?" nos ajuda a esclarecer a narrativa da reportagem e ajuda a fazer reportagens? Estamos a interrogar a prática da reportagem, apenas questionamos a palavra ou visamos a categoria linguística? Cada uma destas condições do ser encaixa-se na palavra reportagem mas não são a mesma coisa.

A prática da reportagem já se fazia muito antes de surgir o conceito. O conceito de reportagem, com a consistência de género jornalístico, só surgiu no final do séc. XIX. 
Será que o nome refere todo o universo da reportagem? Será que é a palavra certa para representar a experiência narrativa que se exerce através da prática da reportagem?

Será que não ilumina apenas um dos lados, o campo jornalístico, anulando ou ocultando os outros campos narrativos atravessados pelo reportar?

Será que não é a própria palavra reportagem, pouco nobre, sem carisma, a responsável pelas narrativas de reportagens serem um saber sujeitado, ou consideradas uma arte menor?

Quando perguntamos pela ontologia da reportagem podemos incluir a perspetiva historicista e perguntar o seguinte: o que aconteceu nas práticas de escrita do real para que, a partir de determinada altura, fossem nomeados pela palavra reportagem?

Esta é a tese defendida por Matilde Rosa Araújo em "A Reportagem como género: génese do jornalismo através do constante histórico-literário":

Com um bocadinho de boa vontade podíamos criar uma tese: que o jornalismo nasceu do verso, como a poesia esteve condenada (felizmente) a fazer nascer a nossa literatura. As notícias infiltram-se. Vem de longe terras, polidas arredondadas, como as pedras de um rio: chegam cá seixos de ribeira (Araújo, 1946: 93).

Rosa Araújo argumenta que já era reportagem aquilo a que no tempo de Fernão Lopes e Pero Vaz Caminha se chamava crónica e que estes terão tido "a arte de chamamento de um verdadeiro repórter artístico e não o empalhado clássico da história" (Araújo, 1946: 101).

Será através do palimpsesto da palavra reportagem que podemos entender o processo de experiência que o ato de reportar, ou melhor o dispositivo da reportagem, põe em marcha? 
Numa anterior investigação seguimos a desconstrução etimológica para chegar à essência da reportagem (Godinho, 2009). No fundo, tentámos interrogar a palavra tentando perceber como ela se pensa e pensa a experiência que produz e que a produz. A base da palavra reportagem é o verbo latim portare que significa "portar" ou "transportar" (Silva, 2014). Se entendermos o portare como "trazer" ou "levar", o prefixo re de reportagem indica, então, que reportar é "trazer novamente" ou "levar de volta". Indica uma repetição do movimento. Esta repetição por mais estranho que pareça é a condição fundamental da narrativa ou, melhor, do dispositivo narrativo.

A narrativa se transporta algo permite-o também transportar de novo. É um caminho que se abre e fica em aberto. É esse o dispositivo. Esta faculdade de uma palavra, como a reportagem, que significa um género narrativo e cuja etimologia apenas aponta para um movimento básico do viver que é transportar, ou carregar, sem indiciar algo mais que clarifique o dispositivo, promete conduzir a análise a um bizarro labirinto.

O que é que se transporta ou carrega? O que é se movimenta ou mobiliza? E o que é que isso tem a ver com o jornalismo?

Uma outra palavra que está muito próxima da palavra reportagem é a palavra "relato" e que por vezes se usa como sinónimo. No latim o significado de relato confunde-se com o de reportar. Relato pode vir de relatus que também significa "carregar", ainda que no sentido de trazer à memória, recordar, ou de relatio ou seja "relativo a" ou "relacionado com". A narrativa de reportagem sendo relato, carrega e transporta para a memória. O quê? Temos duas hipóteses. Os relatos falam de acontecimentos. Portanto, ou se transportam os acontecimentos a alguém ou alguém é transportado até aos acontecimentos.

O essencial neste argumento não é entender a reportagem como o que circula por todo o lado como se fosse uma rede de distribuição dos acontecimentos através das palavras. A reportagem, como narrativa de acontecimentos, configura um dispositivo especial 
que permite estender a básica matriz corporal da experiência. Permite integrar o indivíduo num dispositivo onde viaja junto com os acontecimentos. Dentro das narrativas os acontecimentos viajam, na medida em que são reportados, trazidos de novo à presença mas os sujeitos, na qualidade de leitores, ouvintes ou espectadores também "viajam” (ainda que só através da imaginação) até ao tempo e espaço dos acontecimentos. Dentro das narrativas os acontecimentos tornam-se presentes de novo e por isso se diz que são representados.

O importante a reter, nesta fase da argumentação, é que a faculdade para a qual a palavra reportagem aponta como sinal é para um caminho ou uma porta na experiência. Um caminho que amplia a consciência e uma porta que permite estender as condições de experiência para além do corpo natural. Como é que se justificam, para o sujeito, estas necessidades de movimentação dentro da palavra, de transladação possibilitada pela narrativa e como é que isto nos conduz ao jornalismo?

Deonísio da Silva acrescenta a caminho e porta, a palavra porto porque "na origem remota é a raiz do verbo latino portare, trazer do porto, levar do porto, sentido primitivo que depois se desdobrou em outros tantos significados semelhantes como conduzir, acompanhar, enviar." (Silva, 2014) “Trazer do porto" ou "levar ao porto" são belas imagens que aproximam a palavra reportagem de uma das genuínas atividades do jornalismo, buscando os barcos que chegavam já que era nos portos marítimos que fervilhavam as primeiras notícias e ancoravam todas as histórias de outras paragens.

Também numa anterior investigação (Godinho, 2009) ligámos a essência da reportagem ao antigo vocábulo grego legein o que nos vai permitir aprofundar a reflexão sobre a experiência que se faz dentro de uma narrativa.

Legein ainda hoje é a palavra que os gregos usam para nomear relato e reportagem. Como afirma Manuel António Castro, legein é 
uma palavra fundamental onde "todos os significados estão referenciados pela dinâmica poética da linguagem"63.

Também Heidegger afirma que o fundamental do logos retirámo-lo do legein: "O que é o logos retiramo-lo do legein. O que significa legein? Toda a gente que conheça esta língua sabe: legein significa dizer e falar" (Heidegger, 1994:179). No grego antigo legein significa dizer, relatar, falar, contar, ler. Mas associado ao legein está também o colocar e o posicionar. Temos mais uma vez associada à palavra reportagem, duas vias. Uma diríamos mais verbal e outra mais prática. Será que neste quadro de origem primitiva associada à essência da narrativa de reportagem ficou inscrita apenas a linhagem mais verbal? Como podemos aplicar este fundo do legein, com vários sinónimos, num quadro de pensamento que aprofunde o entendimento da experiência narrativa?

"Colocar diante" é pôr. Colocar várias coisas diante é com-pôr. Uma composição é, portanto, recolher coisas e colocá-las diante do olhar. Dispor para compor. Isto dá-nos uma outra visão para o ler e escrever mas também para o contar. É por esta interpretação conduzida pela via prática do legein que podemos entender porque é que o contar é também sinónimo de narrar, como é que o conto (álgebra) é também conto ou seja uma história como forma de comunicação.

Contar algo a alguém é enumerar coisas, factos, dados, incidentes, ou seja, a reunir tudo numa trama de acontecimentos. É juntar esses dados, compondo-os e dispondo-os para alguém. Contar uma história é alinhar esses dados de maneira a que em conjunto ganhem sentido para outrem.

\footnotetext{
63 "O radical indo-europeu - lg- de legein tem, ao longo do percurso ocidental, realizado toda essa rica gama de significados. Portanto, na raiz de todo é e/ou não-é age a força de legein, uma força de produzir tensões e integrar conflitos, dialeticamente. Dessa maneira, todos os significados de legein estão referenciados pela dinâmica poética da linguagem”. Toda essa rica gama diz respeito a: « $1^{\mathrm{a}}$. Reunir e concentrar; $2^{\mathrm{a}}$. Pausar, assentar e repousar; $3^{\text {a }}$. Listar, relacionar, narrar ou ditar. Só reúne e discerne quem de antemão já vigora no aprender e compreender. É assim que são possibilitados o dizer, as narrativas, a leitura e o diálogo» (Castro, 2013: 14).
} 
Quando contamos algo a alguém, quando escrevemos ou lemos uma narrativa, estamos no fundo a repetir o gesto de um agricultor que colhe, reúne, dispõe e guarda e, assim, produz alimento. Por isso da arte de narrar se extrai o essencial daquilo que se chama a cultura de um povo e o repórter é também, como recoletor, agente de cultura. Percebemos agora, por esta análise conduzida a partir da origem primitiva da reportagem como legein, que o transportar, a mobilização que o dispositivo da reportagem permite, não é o fim pensável do processo narrativo. Reportar não é apenas trazer a alguém os acontecimentos antes ocorridos, "Aquiles morreu", "Ulisses regressou finalmente a Ítaca", "José Sócrates, o ex-primeiro ministro, foi preso".

A reportagem é um dispositivo de mobilização que permite ao leitor/ouvinte/espectador repetir os passos do repórter. É um contar mas fazendo com que o leitor "calce os sapatos" e repita os movimentos do repórter. É esta a experiência que a reportagem permite, uma forma de experimentar os acontecimentos, num processo, numa duração, como se fosse o próprio leitor a recolher e reunir os dados para melhor os conhecer.

Este entendimento da experiência narrativa da reportagem diz-nos que não basta saber que os acontecimentos se deram. Essa é a responsabilidade da notícia (angellô). O dispositivo de mobilização que nos faz "visitar" os acontecimentos no tempo e no espaço não é uma forma de entretenimento.

É a possibilidade de repassar pelos acontecimentos como se tivéssemos sido nós próprios a presenciá-los. Compreende-se então melhor Heidegger para quem a definição primeira do legein é "expor sem intermediários" ${ }^{4}$, ou seja, como se a coisa mesmo estivesse presente. Um bom relato é o que nos dá a sensação de presenciar o

\footnotetext{
${ }_{64}$ "Se escutarmos de maneira grega uma palavra grega, então seguimos seu legein, o que expõe sem intermediários. O que ela expõe é o que está aí diante de nós. Pela palavra grega verdadeiramente ouvida da maneira grega, estamos imediatamente sem presença da coisa mesma, aí diante de nós, e não primeiro apenas diante de uma simples significação verbal" (Heidegger, s/d).
} 
desenrolar dos acontecimentos como se tivéssemos sido nós a vivê-los na condição de testemunhas.

Regressamos elipticamente ao princípio postulado por John Carey quando sustenta que o testemunho é a condição primeira da reportagem. Não é apenas o testemunho do repórter, mas fundamentalmente conta a possibilidade de, através da narrativa, pôr o leitor/ouvinte/ espectador a "testemunhar". Por isso, na verdade, o desejo que o legein exprime não é o de viver de novo os acontecimentos, mas sim de os presenciar, de os testemunhar. Porquê?

Recorremos agora ao pensamento de Hannah Arendt e à sua teoria do espectador (Arendt, 1971) para postular que o desejo de "estar lá" não traduz o desejo de reviver o acontecimento mas o desejo de regressar ao que aconteceu na condição de espectador. O legein como arkhê do reportar, ou seja, da longa tradição do relato na cultura ocidental, não se realiza no desejo de ver tudo, de testemunhar tudo o que aconteceu. Hannah Arendt acrescenta outra função fundamental ao vasto ser-espectador que a narrativa possibilita. Trata-se da vontade de ajuizar, de criticar ou seja de exercer a faculdade de juízo.

O theathai, o ser-espectador realizado na condição humana, reivindica dos deuses o direito a testemunhar os acontecimentos mas também de os julgar. O "voyeurismo" não mobiliza, nem esgota a condição do ser-espectador. É parte de um processo que conduz à complexa fenomenologia do juízo. Exercer um juízo na condição de espectador é o que o dispositivo da narrativa moderna possibilita, criando condições prévias para compreender que, se o que aconteceu é alvo de polémica, então pede um julgamento. Testemunhar um acontecimento à distância, seguindo de forma ordenada os factos e o fio dos acontecimentos com um posicionamento desinteressado, são fases de um dispositivo que pode operar no sentido do mais justo dos juízos - o juízo isento e imparcial - e colocá-lo ao alcance de qualquer pessoa. A simples narrativa de reportagem é, por isso, 
mesmo um complexo (e também democrático) dispositivo de processamento do real.

Diríamos que muitas das narrativas que conhecemos se desviam brutalmente deste objetivo de operativizar a experiência do juízo, disponibilizando-a à condição do sujeito-espectador. Sendo um dispositivo, visa uma experiência sempre em vias de se realizar nas melhores condições possíveis, mas sem ferir o princípio fundamental que é o relato de um acontecimento que aconteceu mesmo. A existência dos acontecimentos nem sempre é fácil de provar nas condições da palavra e da narrativa.

Por isso a reportagem é uma possibilidade, entre outras, na vasta multiplicidade das narrativas modernas e a experiência da crítica e juízo que disputa o legein e competem com as narrativas de ficção.

De que forma competem as reportagens com as ficções?

A argumentação até agora desenvolvida permite-nos responder de forma mais segura à pergunta de Elisabeth Eide What novels can do, and journalism can not? Podemos depois pensar, com outros argumentos, as condições e a eficácia do recentemente chamado jornalismo literário. O jornalismo e a literatura, sobretudo a partir de Mallarmé, tornaram-se categorias alvo de constantes interpretações analíticas e dualistas no campo das ciências humanas. A priori entende-se que existe uma divisão "natural" que separa o jornalismo da ficção e que é a partir dela, por oposição, que se podem definir as características dominantes de cada uma das categorias.

Ao jornalismo associou-se a noção de facto objetivo e estabeleceu-se, como critério definidor, o compromisso das suas narrativas com a realidade. À literatura ligou-se o conceito de ficção como invenção criativa, explorando a imaginação como forma de arte.

O problema é que a ligação do jornalismo à realidade é uma convenção que procura "naturalizar-se" na cultura. O público para acreditar não pode estar sempre a suspeitar de tudo o que lê. Mas as convenções não obedecem a formas universais. Elas resultam daquilo a 
que Roland Barthes chamou o jogo de poder gerado nas "mitologias", ou seja, toda uma série de casos e estórias que alimentam e sustentam a legitimidade do jornalismo, como é exemplo o caso Watergate que se tornou narrativa recorrente nas escolas de jornalismo.

O problema da objetividade tem tido uma influência nas mudanças de estilos, técnicas e géneros do jornalismo. A necessidade de defender a prova de que os factos relatados aconteceram mesmo leva a que o texto noticioso seja entremeado de contextualizações, quebrando a linearidade simples de uma história; recorra a palavras diretas, eliminando a adjetivação mas também despojando o texto de expressões com uma forte carga emocional e que normalmente funcionam nas ficções como embraiadores decisivos para envolver o leitor. É na reportagem que este dilema mais se coloca. Ao aproximar-se do texto de agência para legitimar a objetividade do relatado, o texto de reportagem afasta-se do seu dispositivo natural que é o envolvimento capaz de "mobilizar" o leitor para o legein. Quando as reportagens se afastam do legein, os acontecimentos que dão a conhecer são normalmente apanhados pelas ficções. Tanto a literatura como o cinema conseguem normalmente "oferecer" ações ao leitor e ao espectador que o jornalista, por dever, não consegue descrever porque não o pode provar. As ficções operam, por isso, nas margens em brancas deixadas pelo jornalismo.

A narrativa ficcional aproveita-se da reportagem nos temas e também na forma realística como "arma" as suas narrativas. São muitas vezes histórias baseadas em factos reais, com pormenores inventados mas que poderiam ter acontecido. Têm um poder invulgar de verosimilhança.

A eficácia do cinema em contar histórias reais é não só muito eficaz a mobilizar o interesse do espectador mas também a baralhar as convenções que artificialmente separam a linha entre o real e a ficção. Por isso, alguns jornalistas não resistem à sedução da literatura, recorrendo às técnicas narrativas literárias para depois publicarem reportagens tão densas e pormenorizadas que rivalizavam com os 
filmes. Houve casos de prémios Pulitzer que, mais tarde, foram desmascarados como reportagens inventadas. ${ }^{65}$

Como é que isto pode acontecer? Por um lado, a convenção naturalizada da objetividade, se não for constantemente redefinida, impõe-se como uma autoridade sobre todos os textos jornalísticos. As pessoas acreditam por tradição num jornal ou num telejornal. Escreveu Nietzsche "as verdades são ilusões que nós esquecemos que o são" (Nietzsche, 1999: 57). Mas, pergunta Cristiane Costa:

\begin{abstract}
"a partir de que momento as categorias literatura e jornalismo são naturalizadas e a fronteira entre os dois campos definida? O fato é que, se as fronteiras entre jornalismo e literatura foram construídas a partir de valores bipolares como realidade e imaginação, objectividade e subjectividade, linguagem utilitária e expressiva, significante e significado ou se fazem parte da essência dos dois géneros, o fato é que elas são visíveis" (Costa, s/d:3).
\end{abstract}

Toda a minha argumentação se desenvolve não no sentido de pensar o que separa as categorias de literatura e jornalismo mas o que as une. O que as une é serem narrativa. Como narrativa são uma forma de estruturação da experiência. Todas as narrativas se estruturam a partir do pedido do legein, ou seja, mobilizam um determinado dispositivo de ampliação e mobilização da experiência natural dos indivíduos, conduzindo-os para uma vasta e ubíqua visão testemunhal dos acontecimentos interessantes ocorridos no mundo. Viagem, teatro e tribunal, ou seja, experiência e juízo são as fases deste dispositivo.

\footnotetext{
${ }^{65} \mathrm{O}$ caso mais clássico e por isso mesmo pioneiro aconteceu no respeitável The Washington Post. Uma jovem colaboradora, Janet Cook, publicou uma emocionante reportagem sobre uma criança de oito anos intitulada "Jimmy's World" viciada em heroína injetada pela própria família. A reportagem, cheia de detalhes, venceu meses depois o prestigiado prémio Pullitzer. Mais tarde, descobriu-se que a repórter inventara a história.
} 
O que separa a reportagem da literatura de ficção é que a reportagem, limitada pelo código ético de servir o facto e a verosimilhança, não consegue, com a mesma liberdade da ficção, recriar a proximidade da ação, a intimidade do acontecimento que levariam a realizar de forma perfeita o legein.

Não é por acaso que a maioria das ficções trabalha a partir de casos reais ou com um solo de verosimilhança muito forte. É difícil que uma testemunha assista de perto, por dentro da mente, ao percurso de um assassino ou de um presidente no momento de uma decisão histórica como facilmente acontece na escrita literária.

Os momentos trágicos normalmente são testemunhados em diferido ou inferidos pela ação policial. A ficção opera nas margens da reportagem mas oferecendo aquilo que mais se deseja que é estar o mais perto possível no momento em que o mais importante de um acontecimento acontece mesmo. Ainda que o faça sem garantias de objetividade a ficção oferece o "como se" com uma força que a reportagem não consegue. A ficção não se oferece ao facto mas oferece-se ao juízo.

Reportagem e ficção competem num mesmo campo de experiência que é o da narrativa e do juízo. Por isso, partilham historicamente as mesmas técnicas narrativas. Para Tom Wolf, precursor do jornalismo literário, o "novo jornalismo" é a narrativa que usa técnicas literárias. O crescente interesse pelo jornalismo literário nos últimos anos não é mais que a velha aspiração de conseguir, numa mesma fórmula narrativa, a fusão que concretize a proximidade entre reportagem e ficção e que guarde o melhor das suas experiências na realização do legein. Trabalho complicado. Como guardar o melhor da estrutura narrativa da ficção, a duração, o detalhe, a descrição intensa do encadeado de ações e dos diálogos, sem pôr em causa o factual?

O fogoso investimento no jornalismo literário tem feito com que muitos trabalhos de reportagem percam a credibilidade factual que é o contrato que liga o leitor ao jornalismo e não sejam mais que 
formas de ficção travestidas. Jacques Rancière, ecoando Lacan, também sustenta que o "real para ser pensado precisa de ser ficcionado" (Rancière, 2009). Penso que se trata de uma interpretação demasiado lata do universo das ficções. Poderíamos começar por dizer que o real, para ser pensado, precisa de ser narrado o que significa, no gesto mais genuíno, ser reportado. Refletir a partir de lógicas dualistas que separam o real da ficção, o jornalismo da literatura, é insistir nas categorias que nos aprisionam na interpretação.

Este ensaio pretendeu demonstrar que a "reportagem" montou um dispositivo tão forte e tão exigente que serve de fundação tanto às narrativas do real como às da ficção. São parte do desejo forte e sempre incompleto de realizar o legein. É verdade que a força da ficção e dos seus modelos, a que nos referimos no início deste texto, prova que os filmes e as novelas conseguem aquilo que a reportagem não alcança porque se constata "que a ficção da era estética definiu modelos de conexão entre apresentação dos factos e formas de inteligibilidade que tornam indefinida a fronteira entre razão dos factos e razão da ficção" (Rancière, 2009: 58).

A inteligibilidade do real gerada a partir das narrativas de ficção é tão forte e dominante na construção simbólica da realidade, que vai arrastando sedutoramente os outros campos narrativos. No jornalismo isso é evidente nas modas do infotainment e do jornalismo literário.

Não respondendo a nada definitivamente, este ensaio deixa uma reflexão para trás e uma provocação para a frente. Porque não inverter a lógica da inteligibilidade dominante e pensar antes o que consegue alcançar a reportagem que os filmes não conseguem?

Se realmente o real, para ser pensado, precisa de ser narrado, trata-se de estudar qual a forma narrativa que melhor preserva a qualidade crítica da experiência: a ética tendencialmente objetiva da reportagem jornalística ou a liberdade sem limites da criatividade ficcional. 


\section{REFERÊNCIAS BIBLIOGRÁFICAS}

ARAÚJO, M. R. (1946). A reportagem como género: género do jornalismo através do constante histórico-literário. Tese de licenciatura em Filologia Românica na Faculdade de Letras da Universidade de Lisboa. Biblioteca da Faculdade de Letras de Lisboa.

ARENDT, H. (1971/1999). A Vida do Espírito, col. "Pensar», Vol. I, Lisboa: Instituto Piaget.

BENJAMIN, W. (1936/1994). "O Narrador: Considerações Sobre a Obra de Nikolai Leskov" in Magia e técnica, arte e política: ensaios sobre literatura e bistória da cultura. São Paulo: Brasiliense, pp. 197-221.

BRETON, A. (1926). "Légitime défense " in Point du jour. Paris : Gallimard, pp. 33-36.

CASTRO, M. A. (2013). "Dialéctica e diálogo: a verdade do humano", in Revista TB, 192, Jan. Mar., Rio de Janeiro, p. 14.

CAREY, J. (1996). The Faber Book of Reportage. London: Paperback.

COSTA, C. (s/d). "Fronteiras Cruzadas - A Ficção no Jornalismo e a Reportagem na Literatura", in Revista Z Cultural, n 5 (http://revistazcultural.pacc.ufrj.br/)

DELEUZE, J. (1986 / 2005). Foucault. Lisboa : Edições 70.

DIDEROT, D. (1766). "Hebdomadaires", in Encyclopédie ou Dictionnaire raisonné des sciences, des arts et des métiers, $1^{\text {re }}$ éd. (www.xn-encyclopdie-ibb.eu/S. html) [11-5-2015]

FOUCAUlT, M. (1975). Em Defesa da Sociedade: Curso no Collége de France. São Paulo: Martins Fontes.

GODINHO, J. (2009). Origens da Reportagem: Imprensa. Lisboa: Livros Horizonte.

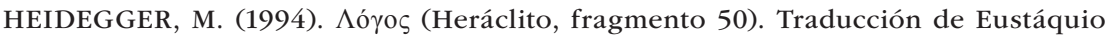
Barjau em Conferencias y artículos. Barcelona: Serbal, pp. 179-199.

HEIDEGGER, M. (s/d). Que é isto - a filosofia? Trad. de Ernildo Stein. http://br.egroups. com/group/acroplis.

MALLARMÉ, S. (1897/ 2011). Crise de Versos. Lisboa: Deriva Editores.

NIETZSCHE, F. (1999). Verdade e Mentir no sentido extra-moral. São Paulo: Nova Cultural.

RANCIÈRE, J. (2009). A partilha do sensível. Estética e Política. São Paulo: Editora 34. 
SILVA, D. (2014). De onde vêm as palavras: origens e curiosidades da língua portuguesa. São Paulo: Léxicon.

STENDHAL (1974). A Cartuxa de Parma. (tradução de Adolfo Casais Monteiro). Porto: Editorial Inova.

VOlTAIRE, F. M. A. (1737). "Conseils à un Journaliste», in CEuvres complètes de Voltaire, éd. Luis Moland. Paris: Garnier, 1877-1885, tome 22. 